\title{
Strengthening digital-based ecotourism through the development of iconic spots in Selorejo Village, Malang Regency
}

\section{Penguatan ekowisata berbasis digital melalui pengembangan spot iconic di Desa Selorejo Kabupaten Malang}

\author{
Vika Annisa Qurrata, Ermita Yusida, Vidya Purnamasari \\ Departemen Ekonomi Pembangunan, Fakultas Ekonomi, Universitas Negeri Malang \\ Jl. Semarang No. 5 Malang, 65145, Indonesia
}

\begin{abstract}
ARTICLE INFO:
\section{ABSTRACT}

Received: 2020-11-02

Revised: 2021-04-20

Accepted: 2021-09-23

Community service activities in the form of strengthening digital ecotourism through iconic spots are carried out to increase tourists' numbers, mostly visits by the millennial generation, which are identical with selfies and social media. This activity is intended for managers and the community of Wana Wisata Bedengan, which are located in Selorejo Village, Malang Regency, totaling ten people. Activities carried out by using the Focus Group Discussion method to socialize and prepare for development, then assist in implementing the construction of iconic photo spots and evaluation of the implementation of the iconic photo spots. In its implementation, the focus group with the manager plays the leading

Keywords: role because the manager provides directions for the location to be added to the iconic photo spot. Community service contributes in the form of physical development of photo spots in the form of iconic main gates, iconic love lights, and iconic life circles. This activity provides conclusions: the number of

Digital-based eco tourism, Iconic spot photo, Social media, tourists visiting is increasing, and the prestige of these tourist attractions will be increasingly famous on social media, especially among the millennial generation.
\end{abstract} Tourism

(C) 2022 Abdimas: Jurnal Pengabdian Masyarakat Universitas Merdeka Malang This is an open access article distributed under the CC BY-SA 4.0 license (https://creativecommons.org/licenses/by-sa/4.0/)

How to cite: Qurrata, V. A., Yusida, E., \& Purnamasari, V. (2021). Strengthening digital-based ecotourism through the development of iconic spots in Selorejo Village, Malang Regency. Abdimas: Jurnal Pengabdian Masyarakat Universitas Merdeka Malang, 7(1), 28-37. https://doi.org/10.26905/abdimas.v7i1.4979

\section{PENDAHULUAN}

Pariwisata merupakan salah satu motor penggerak perekonomian Indonesia, sehingga sektor ini menjadi prioritas utama dibandingkan dengan sektor lainnya. Percepatan pertumbuhan ekonomi dapat ditopang dengan salah satu cara yaitu majunya industri pariwisata. Dengan adanya pariwisata, permintaan terhadap barang dan jasa akan meningkat karena peningkatan permintaan wisatawan. Dampak dari kenaikan permintaan ini adalah semakin banyaknya investasi di bidang akomodasi yang 
mendukung pariwisata seperti bidang transportasi dan komunikasi, perhotelan, industri kerajinan, serta restoran (Spillane, 2004).

Walaupun saat ini pariwisata juga menjadi sektor yang paling terpukul dengan adanya COVID-19 akan tetapi aktivitas wisata mulai bangkit kembali walaupun belum setinggi dahulu. Tren wisata saat ini berubah dengan adanya kebijakan New Normal yang ditetapkan oleh pemerintah sejak Juni 2020. Tren wisata yang telah berubah di antara lain yaitu pemilihan wisata alam yang banyak menjadi tujuan serta pemilihan wisata domestik. Hal ini diakibatkan keinginan wisatawan untuk menikmati pemandangan alam menyebabkan potensi agrowisata (wisata berbasis alam) berkembang daya tariknya (Koswara, 2005).

Dengan adanya perubahan tren wisata domestik, pembangunan tidak akan bisa maksimal jika tidak ada integrasi antara dua pilar utama yaitu pemerintah daerah dan masyarakat. Nyatanya, masih terdapat beberapa kelemahan dalam konteks pembangunan daerah, yaitu masih adanya permasalahan dalam bidang kelembagaan serta pengelolaan. Pengelolaan sendiri tentunya membutuhkan keterkaitan antara lembaga kemasyarakatan, instansi swasta, dan masyarakat (Syaodih, 2015). Salah satu rencana pembangunan adalah berbentuk pengembangan desa wisata. Desa wisata dapat berjalan dengan baik apabila ada koordinasi yang tepat antara pemerintah, sektor swasta, masyarakat, akademisi, serta media. Tentunya dengan dimunculkan potensi unggulan dalam pengembangan desa berupa desa wisata akan mempercepat proses penguatan ekonomi desa (Sukoco, 2018). Harapannya adalah desa wisata ini dapat mendukung perubahan pendapatan masyarakat sekitar (Miswanto \& Safaat, 2018; Fitriani \& Wilardjo, 2017).

Salah satu strategi yang diharapkan oleh pemerintah dapat memperkuat pengembangan wisata alam ataupun wisata desa adalah kolaborasi Model Pentahelix. Model ini dirancang untuk meningkatkan nilai manfaat kepariwisataan pada masyarakat dan lingkungan melalui integrasi antara kualitas aktivitas, fasilitas, serta pelayanan dari pengelola pada wisatawan. Untuk memenuhi tercapainya Model Pentahelix ini maka dibutuhkan dorongan optimalisasi sektor kepariwisataan melalui peranan 5 sektor yaitu pengusaha, pemerintah, komunitas, akademisi, dan media. Model Pentahelix, menurut Soemaryani (2016), dibutuhkan untuk mencapai tujuan dengan memaksimalkan sinergi antara instansi pemerintah, masyarakat, serta swasta. Apabila kolaborasi ini telah tercapai, maka inovasi untuk kemajuan sosial ekonomi suatu daerah akan mudah dilaksanakan (Halibas et al., 2017).

Jawa Timur terutama Kabupaten Malang terkenal akan wisata alamnya yang indah. Sehingga daerah ini terkenal sebagai destinasi wisata alam. Tidak hanya pantai, coban, dan sumber saja, bahkan sebuah bedengan pun bisa dijadikan lokasi wana wisata di sini. Salah satunya adalah Wana Wisata Bedengan di Dusun Selokerto, Desa Selorejo, Kecamatan Dau yang menyimpan kesejukan khas dataran tinggi. Lokasi nya berada pada daerah Kabupaten Malang bagian utara. Wana Wisata Bedengan ini dibuka mulai tahun 2007 silam dengan luas 13,7 hektar. Sebelum dibuka untuk umum sebagai tempat wisata, tempat ini sejatinya adalah lahan untuk pembibitan tanaman pohon mahoni yang biasa disebut bedeng yang dikelola Perhutani sehingga lokasi ini dinamakan Bedengan. Meski dimiliki oleh Perhutani, tapi pengelolaan hariannya dilakukan oleh pihak Lembaga Kemitraan Desa Pengelola Hutan (LKDPH) Desa Selorejo yang merupakan lembaga di bawah Kesatuan Pemangku Hutan (KPH) Kabupaten Malang. Warga desa setempat mengelola fasilitas-fasilitas yang ada di wana wisata ini melalui Pokdarwis yang diketuai oleh Pak Sulistyono.

Desa yang terletak di dataran tinggi ini memiliki kesejukan dan kesegaran udara. Sepanjang area pemandangan alam nan hijau pohon pinus serta sungai yang mengalir menjadi pesona alam utama di desa ini. Di lokasi ini terdapat pula hutan pinus seluas 2,5 hektar yang dapat digunakan berkemah dan bermain outbond. Area ini dikelola oleh Pokdarwis yang merupakan warga-warga sekitar desa tersebut. 
ABDIMAS: Jurnal Pengabdian Masyarakat Universitas Merdeka Malang

Volume 7, No 1, February 2022: 28-37

Selama ini, dominasi wisatawan yang berkunjung di sini adalah keluarga, pelajar, dan mahasiswa. Masalah prioritas yang dihadapi oleh Wana Wisata Bedengan dan membutuhkan penyelesaian melalui pelaksanaan program PKM (Pengabdian Kepada Masyarakat), yaitu: (1) Minimnya sarana yang dikembangkan karena sumber daya alam yang ada belum dimaksimalkan untuk menarik minat wisatawan. Pengelola hanya menawarkan wisata alam saja, bahkan penerangan seperti lampu juga sangat minim; (2) Kurangnya pengelolaan dengan konsep ekonomi digital padahal saat ini merupakan era tourism 4.0. Tourism 4.0 dikenal pula sebagai Millenial Tourism sehingga 50 persen inbound traveller adalah millenial. Pada saat travelling, 70 persen pengguna sosial media menggunggah foto dan status mereka saat berlibur. Dengan demikian, jika pengelola tidak melakukan pembenahan melalui hal yang paling sederhana seperti pembuatan spot foto iconic untuk lokasi mengunggah foto atau video tentang destinasi yang dikunjungi ke media sosial, maka dikhawatirkan lokasi wisata ini akan ditinggalkan. Peran media sosial menjadi penting dalam peningkatan jumlah pengunjung karena berdasarkan Haq (2019), media sosial utamanya Instagram paling berpengaruh terhadap peningkatan jumlah pengunjung dibandingkan dengan media sosial Facebook dan Twitter.

Untuk menghindari terjadinya lokasi wisata yang ditinggalkan, maka keunggulan bersaing suatu daerah destinasi wisata akan muncul jika pengelola memiliki kemampuan untuk meningkatkan pengetahuan, keterampilan, keahlian, dan sumber daya lainnya (Kotler et al., 2004). Pengelola juga harus memiliki strategi kolaborasi untuk meningkatkan keunggulan destinasi wisata. Berdasarkan Wang \& Pizam (2011), strategi yang harus dimiliki yaitu penguatan visi, penguatan komitmen, penguatan identitas, serta penguatan kondisi dari lokasi wisata tersebut. Penelitian Mu'izzah (2019) serta Rakhmawati (2017) juga mendukung hasil penelitian di atas bahwa kualitas fasilitas wisata berpengaruh pada kepuasan pengunjung karena semakin banyak pengunjung yang hadir ke objek wisata menjadi salah satu indikator keberhasilan pengelolaan lokasi wisata.

Program ini memiliki tujuan untuk merevitalisasi Bumi Perkemahan Bedengan yang terletak di Desa Selorejo, Kecamatan Dau, Kabupaten Malang menjadi rujukan wisata bagi generasi milenial. Tim pengusul program pengabdian kepada masyarakat telah memilih konsep Ekowisata Digital yang sangat cocok untuk generasi milenial dengan jiwa travellernya. Ekowisata Digital merupakan konsep tempat wisata yang tidak hanya digunakan untuk menikmati keindahan alam, namun juga terdapat spot foto iconic yang bisa digunakan oleh para pengunjung untuk diunggah di media sosial ataupun sebagai kenangan-kenangan. Dengan demikian, jumlah pengunjung yang datang juga akan semakin meningkat.

\section{METODE}

Program pengabdian kepada masyarakat ini dilakukan di Bumi Perkemahan Bedengan yang terletak di Desa Selorejo, Kecamatan Dau, Kabupaten Malang. Mitra yang terlibat merupakan kelompok masyarakat yang selama ini menjadi pengelola di daerah tersebut. Di awal sebelum kegiatan, tim pelaksana melakukan pra-survei di daerah tersebut dan hasilnya adalah Bumi Perkemahan Bedengan memiliki potensi alam yang luar biasa untuk dikembangankan. Akan tetapi keterbatasan fasilitas yang ditawarkan kepada pengunjung menjadi salah satu hambatan dalam pengembangan lokasi wisata alam ini. Sehingga tim pelaksana memberikan solusi berupa penambahan spot foto iconic untuk menarik keinginan wisatawan berkunjung kesana. Dalam pelaksanaannya, kegiatan pengabdian kepada masyarakat ini menggunakan pendekatan Focus Group Discussion. Untuk mencapai tujuan tersebut, langkah-langkah yang harus dilakukan agar tujuan pengabdian tercapai. Langkah-langkah tersebut digambarkan dalam Gambar 1. 


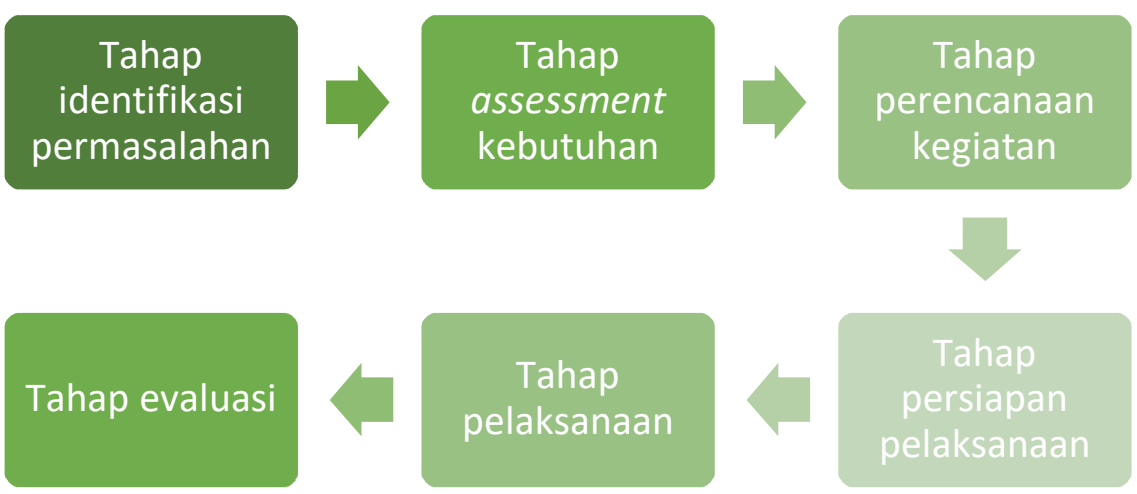

Gambar 1. Langkah-langkah pelaksanaan kegiatan

\section{Tahap identifikasi permasalahan}

Dalam tahapan ini, wawancara dan pengamatan langsung dibutuhkan untuk mengetahui faktorfaktor yang menjadi permasalahan mitra. Dalam tahap ini, setiap anggota masyarakat yang tergabung dalam Pokdarwis akan diminta untuk berkomitmen mengawal proses penguatan potensi wisata di daerah ini mulai dari awal sampai akhir. Proses komitmen ini membutuhkan musyawarah atau kesepakatan antara tim pelaksanaan dengan Pokdarwis. Proses ini dilakukan pada bulan Januari 2020 melalui Focus Group Discussion (FGD). Metode ini dipilih agar seluruh partisipan berkomitmen dan terlibat dalam pembangunan partisipatif.

\section{Tahap assessment kebutuhan}

Tahap kedua merupakan perwujudan dari identifikasi permasalahan yaitu berupa assessment kebutuhan. Tim pelaksana serta Pokdarwis yang terlibat harus bisa menyimpulkan kebutuhan utama masyarakat di daerah wisata alam. Kebutuhan utama ini nantinya akan menjadi visi dan misi serta tujuan akhir dari program pengabdian kepada masyarakat ini. Studi lapangan untuk memenuhi kebutuhan utama pengelola wisata alam ini dilakukan pada Maret 2020.

\section{Tahap perencanaan kegiatan}

Perencanaan kegiatan ini dilakukan pada Mei 2020 dilakukan berdasarkan hasil studi lapangan. Serangkaian kegiatan yang akan dilakukan selanjutnya tentu akan membutuhkan perencanaan anggaran, langkah strategis, tahapan pekerjaan teknis, pembagian peran, dan tugas serta antisipasi adanya kesulitan dalam pelaksanaan. Semua proses yang dilakukan di atas tentunya membutuhkan hasil penilaian dari studi lapangan yang telah dilakukan di tahapan sebelumnya.

\section{Tahap persiapan pelaksanaan}

Persiapan pelaksanaan ini membutuhkan koordinasi antara tim universitas, pengelola, serta masyarakat. Pada Juni 2020, tim dari universitas memilih agar pembangunan fisik di lokasi dilakukan oleh masyarakat yang diawasi oleh pengelola. Harapannya adalah dengan dilibatkannya masyarakat dalam proses ini, maka mereka juga mau ikut terlibat dalam proses perawatan lokasi setelah pembangunan terjadi.

\section{Tahap pelaksanaan}

Pelaksanaan bantuan revitalisasi Ekowisata Digital Desa Bedengan melalui pembuatan main gate iconic, love light iconic, serta life circle iconic dilakukan mulai Juli sampai September 2020. Dalam tahap 
ABDIMAS: Jurnal Pengabdian Masyarakat Universitas Merdeka Malang

Volume 7, No 1, February 2022: 28-37

pelaksanaan, Pokdarwis melalui karang taruna dan warga sekitar akan membantu dalam pembangunan fisik.

\section{Tahap evaluasi}

Tim pelaksana melakukan evaluasi akhir mulai Oktober hingga November 2020. Evaluasi akhir dilakukan dengan pengamatan dari hasil perbaikan berupa pembuatan main gate iconic, love light iconic, serta life circle iconic. Mitra diharapkan akan lebih terbuka dan aktif dalam perawatan fasilitas yang diberikan. Keberlanjutan program dapat dilakukan melalui monitoring atas dampak dari keberadaan revitalisasi ekowisata digital Desa Bedengan. Monitoring secara kuantitatif dapat dilihat dari peningkatan jumlah pengunjung dan peningkatan jumlah retribusi.

\section{HASIL DAN PEMBAHASAN}

Hasil dan pembahasan program pengabdian kepada masyarakat berupa focus group discussion serta pemberian bantuan berupa fasilitas ke Wana Wisata Desa Bedengan dibagi menjadi enam tahap.

\section{Tahap identifikasi permasalahan}

Prinsip pembangunan yang berpusat pada rakyat menegaskan bahwa masyarakat harus menjadi pelaku utama dalam pembangunan. Sehingga dalam tahapan ini, tim pengabdian melalukan focus group discussion untuk mengidentifikasi permasalahan utama yang dihadapi pengelola dan masyarakat terkait dengan kebutuhan fasilitas mereka. Dalam sesi ini, masyarakat dan pengelola berperan aktif dalam menunjukkan inisiatif dan kreatif dalam mengatasi permasalahan yang muncul di sekitarnya. Sementara tim yang berasal dari akademisi dalam pelaksanaan pengabdian kepada masyarakat harus memiliki kemampuan dalam menciptakan sistem pembangunan agar pemberdayaan masyarakat secara partisipatif dapat dilaksanakan seperti yang ditulis oleh Adimihardja \& Hikmat (2003).

Dalam proses ini, terdapat beberapa permasalahan fasilitas yang dihadapi oleh pengelola serta masyarakat seperti: (1) Tidak adanya penerangan jalan yang layak di sepanjang jalan masuk Wana Wisata Bedengan; (2) Jalan yang sempit dan masih berupa batu geragal sehingga kendaraan terutama roda empat sedikit kesulitan mengakses apabila berpapasan dengan kendaraan lain; (3) Jembatan yang dibangun di atas sungai merupakan jembatan kayu, bukan jembatan permanen; serta (4) Kurangnya fasilitas untuk pengunjung untuk berfoto dan melakukan aktivitas selain berkemah.
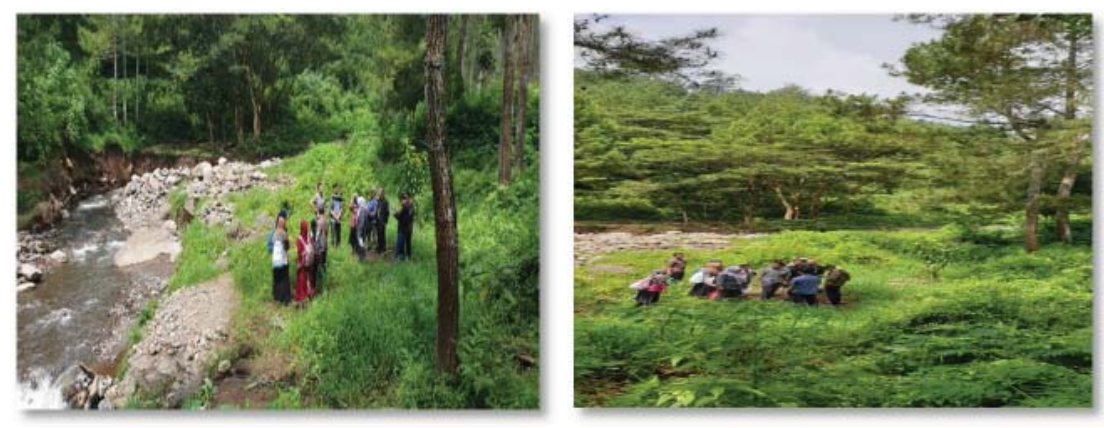

Gambar 2. Tahap identifikasi permasalahan

\section{Tahap assessment kebutuhan}

Berdasarkan permasalahan yang dihadapi di atas, maka tim pengabdian, pengelola, dan masyarakat menyepakati untuk melakukan perbaikan pada fasilitas pengunjung seperti spot foto. Keputusan ini 
diambil berdasarkan penilaian kebutuhan yang paling penting menurut pengelola dan masyarakat. Dengan adanya spot foto yang menarik, harapannya adalah kunjungan wisatawan akan meningkat.

Dalam tahapan ini, tim berserta pengelola dan masyarakat menyepakati membuat gate iconic, love light iconic, serta life circle iconic. Pengelola menunjukkan blueprint pengembangan Kawasan Wana Wisata Bedengan kepada tim sehingga tim bisa mengetahui dimana lokasi pemasangan spot foto yang layak. Pemilihan lokasi ini juga atas pertimbangan serta persetujuan pengelola. Kesepakatan yang diperoleh adalah gate iconic dipasang pada jalan masuk setapak untuk wisatawan, love light iconic dipasang pada tiap pohon sepanjang 500 meter dari jalan masuk, dan life circle iconic dipasang dekat dengan daerah sungai dengan latar belakang pohon pinus dan sungai di belakang nya.
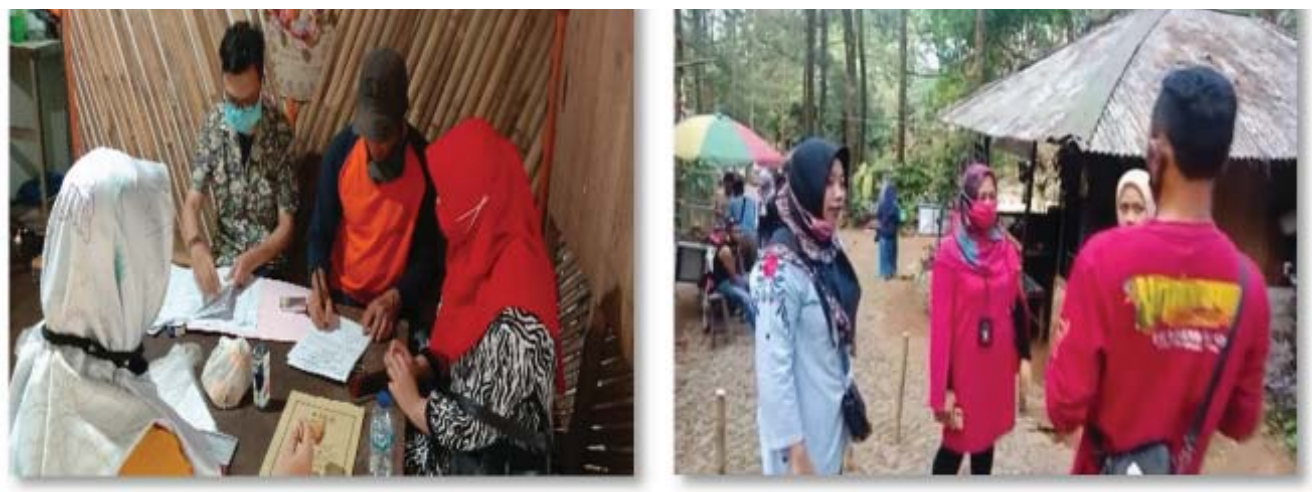

Gambar 3. Tahap assessment kebutuhan dengan pengelola

\section{Tahap perencanaan kegiatan}

Tahapan ini memiliki empat dasar perencanaan meliputi: (1) Menetapkan tujuan; (2) Merumuskan keadaan; (3) Mengidentifikasi kemudahan dan hambatan; (4) Mengembangkan rangkaian kegiatan untuk pencapaian tujuan. Tujuan dari kegiatan ini adalah agar pelaksanaan pembangunan fasilitas dapat dengan cepat dan tepat terlaksana. Keadaan yang ada di Wana Wisata Bedengan adalah banyak masyarakat yang mau berpartisipasi dalam proses pembangunan akan tetapi tidak ada yang sanggup mengerjakan gate iconic serta life circle iconic sehingga tim, masyarakat, dan pengelola memutuskan untuk melakukan pemesanan pada tukang logam. Desain dari gate iconic serta life circle iconic digambar oleh tim pengabdian yang diserahkan pada tukang logam untuk membuat serta merakitnya. Kemudahan yang ada Wana Wisata Bedengan adalah tersedianya batu sungai yang melimpah sehingga itu bisa dijadikan tatakan jalan menuju spot life circle iconic.
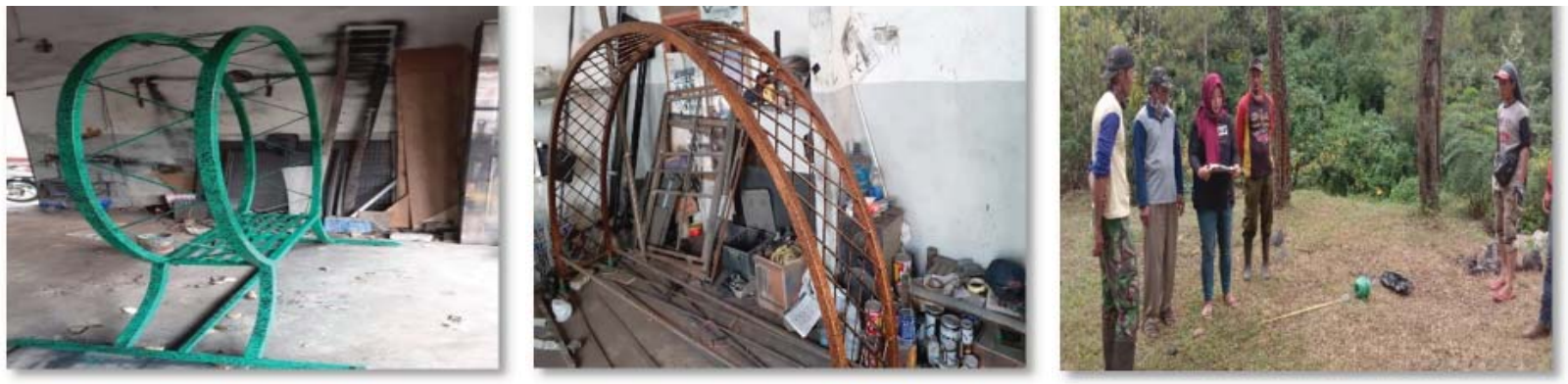

Gambar 4. Rangka besi gate iconic dan life circle iconic yang akan dipasang

Gambar 5. Tahap persiapan kegiatan 
ABDIMAS: Jurnal Pengabdian Masyarakat Universitas Merdeka Malang

Volume 7, No 1, February 2022: 28-37

\section{Tahap persiapan pelaksanaan}

Persiapan pelaksanaan dibutuhkan untuk mengetahui seberapa banyak material serta sumber daya manusia yang dibutuhkan. Dalam proses ini, tim pengabdian dibantu oleh pengelola untuk berbelanja material serta penyediaan tenaga kerja untuk proses pembuatan jalan setapak menuju spit iconic berupa life circle iconic. Sementara itu di tempat lain, tukang logam telah membuat serta merakit desain gate iconic serta life circle iconic yang nantinya akan dipasang pada saat pelaksanaan pengabdian kepada masyarakat. Gambar 5 merupakan gambar gate iconic serta life circle iconic yang nantinya dipasang di Wana Wisata Bedengan.

\section{Tahap pelaksanaan}

Pelaksanaan dari pengabdian kepada masayarakat ini ditandai dengan penyerahan fasilitas spot iconic yang telah disiapkan oleh tim pengabdian kepada masyarakat. Dengan adanya spot foto iconic ini diharapkan pengunjung Wana Wisata Bedengan ini semakin meningkat. Selain itu, para pengunjung yang datang diharapkan akan mengunggah foto mereka pada akun media sosial yang mereka miliki sehingga banyak orang yang akan tertarik untuk mengunjungi daerah ini. Dengan banyaknya wisatawan yang hadir, peningkatan ekonomi masyarakat sekitar akan dapat tercapai.
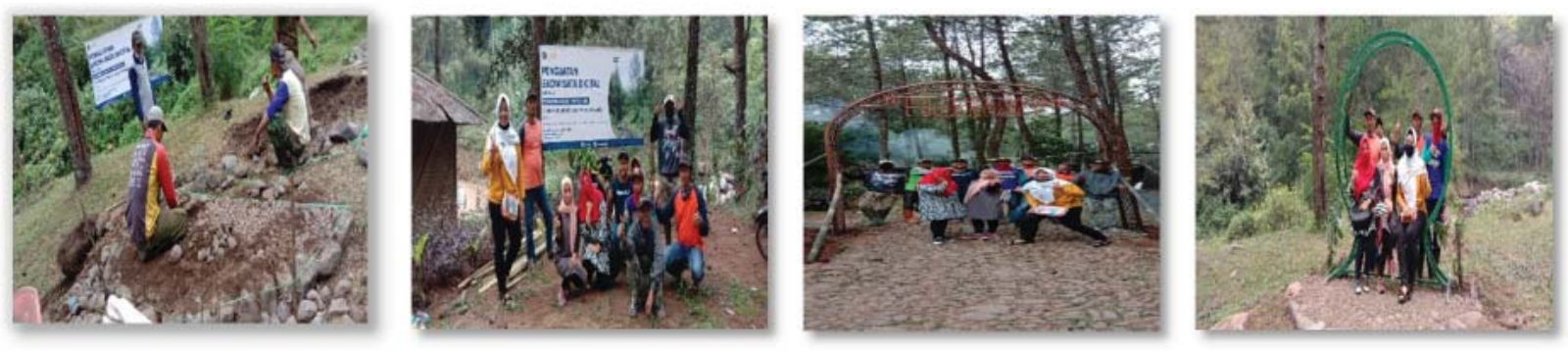

Gambar 6. Pelaksanaan pemasangan bantuan fasilitas spot foto iconic

Gambar 7. Bantuan yang diberikan

Pada Gambar 6 dan Gambar 7 terlihat bahwa tim pengabdian berfoto bersama pengelola serta karang taruna dan warga sekitar yang membantu proses pembangunan serta peletakan dari spot foto iconic. Pemilihan sumber daya manusia dalam pembangunan mencakup masyarakat dan karang taruna karena tim pengabdian berharap bahwa fasilitas spot foto iconic nantinya akan selalu dalam perawatan dari pengelola dan masyarakat. Hal ini penting karena suatu tempat wisata membutuhkan pelestarian dan kebersihan yang harus tetap terjaga sehingga pengunjung yang datang akan tetap kembali. Hasil penelitian dari Prameswari et al. (2018) menyatakan bahwa kepuasan pengunjung akan terbentuk jika fasilitas tempat wisata tersebut dalam keadaan yang baik serta terawat. Sehingga untuk meningkatkan kepuasan wisatawan, maka hal utama yang harus dilakukan adalah menjaga agar fasilitas tetap terawat serta melakukan penambahan fasilitas yang ada.

\section{Tahap Evaluasi}

Tahap terakhir dari kegiatan ini adalah evaluasi. Evaluasi akan diukur dari seberapa banyak peningkatan jumlah wisatawan setelah adanya spot foto iconic, peningkatan retribusi bagi pengelola serta jumlah postingan di media sosial. 


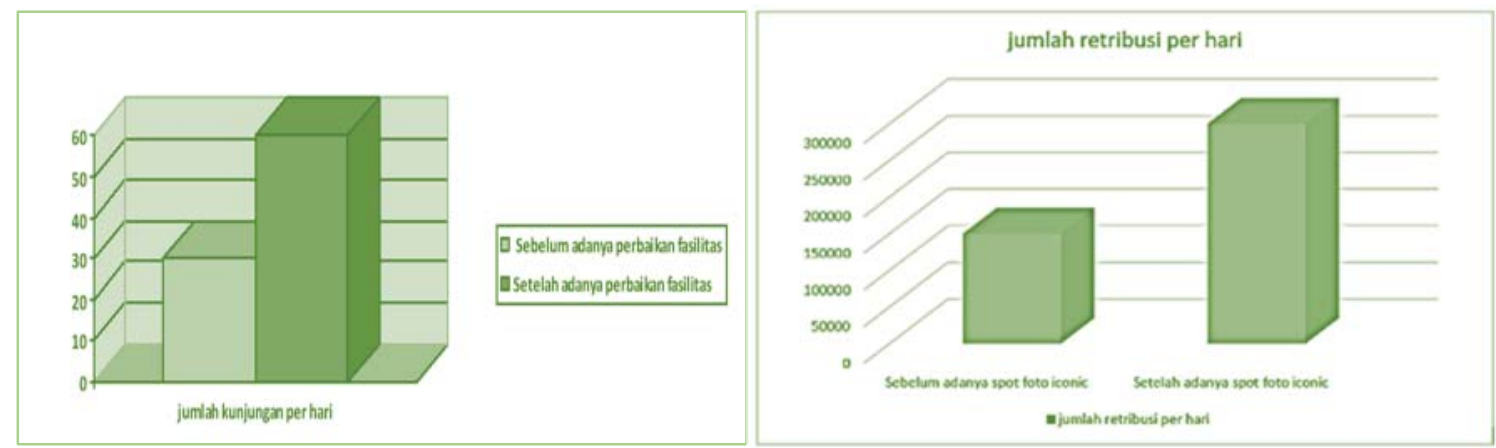

Gambar 8. Perbandingan jumlah kunjungan wisatawan per hari

Gambar 9. Perbandingan retribusi per hari

Dari Gambar 8 dapat disimpulkan bahwasanya terdapat peningkatan pengunjung yang signifikan setelah adanya spot foto iconic di Wana Wisata Bedengan. Hal ini sejalan dengan penelitian oleh Mu'izzah (2019) dan Rakhmawati (2017) yang menyimpulkan bahwasannya kualitas fasilitas wisata berpengaruh pada kepuasan pengunjung. Dengan adanya penambanhan spot foto iconic yang menambah kualitas pada fasilitas wisata memberikan dampak positif pada penambahan jumlah pengunjung sebesar $100 \%$ dari sebelum adanya spot iconic.

Selain peningkatan jumlah pengunjung, jumlah retribusi menunjukkan peningkatan 100 persen dari sebelum adanya spot iconic. Hal ini sejalan dengan penelitian oleh George (2010), yang menyimpulkan bahwasanya penguatan pada fasilitas wisata yang semakin inovatif, kreatif, dan mengikuti arus perkembangan memberikan feedback yang dapat menggerakkan dan mendukung basis ekonomi lokal sekitar tempat pariwisata.
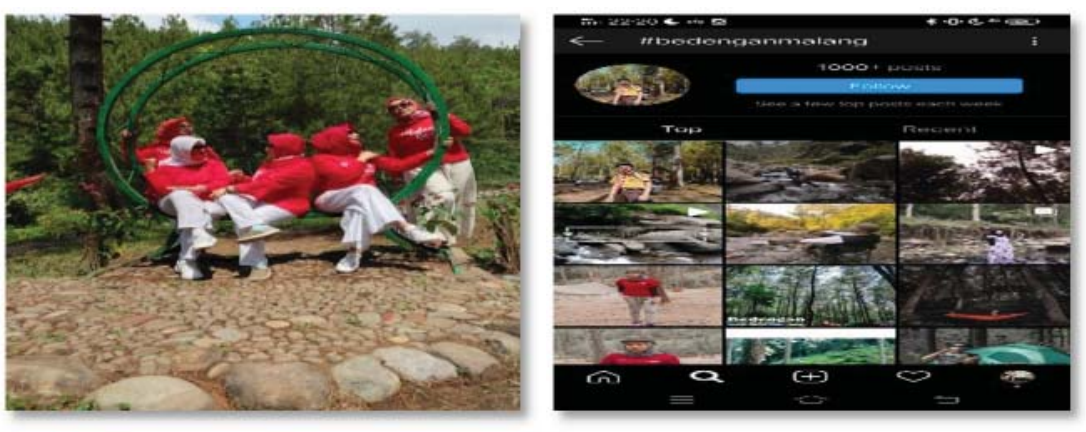

Gambar 10. Perkembangan lokasi dan media sosial setelah mendapat bantuan

Serangkai spot foto iconic disambut dengan sangat antusias oleh pengunjung sebagai spot foto kekinian yang menambah kesan artistik yang mendukung suasana alam di Wana Wisata Bedengan. Di sisi lain, pengelola dari pihak pariwisata pula menyambut hangat akan program pengabdian yang memberikan sumbangsih inovasi dan support pada pengelolaan tempat wisata guna mengangkat ekonomi lokal di sekitar tempat pariwisata. Terlebih pada era Tourism 4.0 atau Millenial Tourism yang cenderung mengunggah foto kala melakukan travelling. Sehingga penambahan pada spot foto memberikan penambahan preferensi bagi pengunjung untuk berfoto atau berswafoto untuk koleksi pada akun media sosial. Sejalan dengan penelitian Haq (2019), media sosial utamanya Instagram paling 
ABDIMAS: Jurnal Pengabdian Masyarakat Universitas Merdeka Malang

Volume 7, No 1, February 2022: 28-37

berpengaruh terhadap peningkatan jumlah pengunjung dibandingkan dengan media sosial Facebook dan Twitter.

Hal ini dibuktikan dengan unggahan dengan tagar \#bedenganmalang yang mencapai $1000+$ unggahan pada platform media sosial Instagram (Gambar 10). Dengan adanya penambahan spot iconic, memberikan tambahan pengunjung yang datang untuk berwisata serta mengabadikan momen dan mengunggahnya di berbagai platform media sosial. Pengunjung menjadi termotivasi untuk mengujunggi wisata lokal dengan daya tarik wisata yang berbasiskan alam (wisata agro) menjadi potensial (Koswara, 2005). Dengan dukungan perkembangan digital, insight mengenai pariwisata lokal dapat di-tracking agar menarik preferensi pengunjung secara berkesinambungan serta meningkatkan pamor di Wana Wisata Bedengan.

\section{SIMPULAN DAN SARAN}

Kesimpulan dari kegiatan pengabdian yang berupa kegiatan pengabdian berupa penguatan ekowisata digital melalui pengembangan spot iconic. Selaras dengan tujuan pengabdian, spot iconic berhasil meningkatkan jumlah pengunjung dan meningkatkan retribusi sebesar 100 persen dari sebelum adanya spot foto iconic. Terlebih, terdapat 100+ unggahan dengan tagar \#bedenganmalang pada platform media sosial Instagram.

Saran yang dapat diberikan untuk pengabdian selanjutnya yakni: (1) Perlu adanya SOP pada pengunjung serta protokoler COVID-19 agar Wana Wisata Bedengan tetap dapat beroperasi dengan tetap memperhatikan keselamatan serta kenyamanan pengunjung; (2) Diperlukan adanya pembentukan tim promosi online dan tour guide yang merupakan bagian dari karang taruna Desa Bedengan agar wisatawan yang berasa dari luar daerah Malang dapat berkunjung dengan rasa aman; (3) Perlu adanya pengelolaan yang lebih terstruktur mulai dari pengelolaan tempat wisata dan pendapatan serta retribusi yang didapatkan agar pengawasan serta pengelolaan lanjutan dapat dilakukan dengan efektif.

\section{UCAPAN TERIMA KASIH}

Pengabdian Kepada Masyarakat ini dapat terlaksana dengan adanya pendanaan hibah Pengabdian kepada Masyarakat LP2M Universitas Negeri Malang tahun 2020.

\section{DAFTAR PUSTAKA}

Adimihardja, K., \& Hikmat, H. (2003). Participatory Research Appraisal dalam pelaksanaan pengabdian kepada masyarakat. Bandung: Humaniora.

Fitriani, R \& Wilardjo, S.B. (2017). Sadar wisata, kemenarikan fasilitas, jarak, pengaruhnya terhadap minat berkunjung kembali pada objek wisata Masjid Agung Jawa Tengah di Kota Semarang. Jurnal Wawasan Manajemen, 5(3), 259-272. http://dx.doi.org/10.20527/jwm.v5i3.121

George, W. E. (2010). Intangible cultural heritage, ownership, copyrights, and tourism international. Journal of Culture, Tourism and Hospitality Research, 40(4), 376-388. https://doi.org/10.1108/17506181011081541

Halibas, A. S., Sibayan, R. O., \& Maata, R. L. R. (2017). The Pentahelix Model of innovation in Oman: An HEl perspective. Interdisciplinary Journal of Information, Knowledge, and Management, 12. https://doi.org/10.28945/3735 
Haq, H. Z. (2019). Pengaruh media sosial (Facebook, Twitter, Instagram) terhadap peningkatan jumlah pengunjung kolam renang di Kabupaten Malang. Skripsi. Universitas Negeri Semarang.

Koswara, I. H. (2005). Karakteristik dan Potensi Wisata Agro Jawa Barat. In Forum Koordinasi Pengembangan Wisata Agro Jawa Barat tanggal 7 Desember 2005 Bandung.

Kotler, P., Bowen, J \& Makens, J. (2006). Marketing for hospitality and tourism. $4^{\text {th }}$ Edition. Prentice Hall.

Miswanto \& Safaat, M. (2018). Dampak pembangunan industri pariwisata terhadap alih fungsi lahan (Studi tentang kehidupan sosial budaya masyarakat Desa Teluk Bakau, Kecamatan Gunung Kijang, Kabupaten Bintan, Kepulauan Riau). Jurnal Antropologi, 20(1), 45-55. https://doi.org/10.22146/jnp.59463

Mu'izzah, I. (2019). Pengaruh kualitas fasilitas wisata terhadap kepuasan pengunjung pada Taman Mini Indonesia Indah Jakarta. Skripsi. Universitas Sahid Jakarta.

Prameswari, P. I., Nawangsih, N., \& Sulistyan, R. B. (2018). Identifikasi preferensi pengunjung terhadap destinasi wisata. In Proceedings Progress Conference, 1(1), 138-145.

Rakhmawati, E. (2021). Pengaruh atraksi wisata, fasilitas, dan novelty seeking terhadap kepuasan pengunjung Desa Wisata Pasar Pereng Kali Kemit, Kebumen [Doctoral dissertation, Universitas Putra Bangsa].

Soemaryani, I. (2016). Pentahelix model to increase tourist visit to Bandung and its surrounding areas through human resource development. Academy of Strategic Management Journal, 15(3), 249259.

Spillane, J. J. (2004). Ekonomi pariwisata sejarah dan prospeknya. Yogyakarta: Kanisius.

Sukoco, J. B. (2018). Pemberdayaan masyarakat dalam pengelolaan Desa Wisata Kaki Langit di Desa Mangunan Kecamatan Dlingo Kabupaten Bantul. In Slamet Riyadi Conference on Public Administration (SRIPA).

Syaodih, E. (2015). Manajemen pembangunan kabupaten dan kota. Bandung: Aditama

Wang, Y., \& Pizam, A. (2011). Destination marketing and management: Theories and applications. Oxford: CABI Publishing. 